\title{
Assessment of water quality management with a systematic qualitative uncertainty analysis
}

\author{
Chi-Feng Chen ${ }^{\text {a }}$, Hwong-wen Ma ${ }^{a}$, , Kenneth H. Reckhow ${ }^{\mathrm{b}}$ \\ ${ }^{a}$ Graduate Institute of Environmental Engineering, National Taiwan University, Taipei, Taiwan \\ ${ }^{\mathrm{b}}$ Division of Environmental Science and Policy, Nicholas School of the Environment and Earth Sciences, Duke University, Durham, NC, USA
}

Received 28 June 2006; received in revised form 4 December 2006; accepted 6 December 2006

Available online 25 January 2007

\begin{abstract}
Uncertainty is an inevitable source of noise in water quality management and will weaken the adequacy of decisions. Uncertainty is derived from imperfect information, natural variability, and knowledge-based inconsistency. To make better decisions, it is necessary to reduce uncertainty. Conventional uncertainty analyses have focused on quantifying the uncertainty of parameters and variables in a probabilistic framework. However, the foundational properties and basic constraints might influence the entire system more than the quantifiable elements and have to be considered in initial analysis steps. According to binary classification, uncertainty includes quantitative uncertainty and non-quantitative uncertainty, which is also called qualitative uncertainty. Qualitative uncertainty originates from human subjective and biased beliefs. This study provides an understanding of qualitative uncertainty in terms of its conceptual definitions and practical applications. A systematic process of qualitative uncertainty analysis is developed for assisting complete uncertainty analysis, in which a qualitative network could then be built with qualitative relationship and quantifiable functions. In the proposed framework, a knowledge elicitation procedure is required to identify influential factors and their interrelationship. To limit biased information, a checklist is helpful to construct the qualitative network. The checklist helps one to ponder arbitrary assumptions that have often been taken for granted and may yield an incomplete or inappropriate decision analysis. The total maximum daily loads (TMDL) program is used as a surrogate for water quality management in this study. 15 uncertainty causes of TMDL programs are elicited by reviewing an influence diagram, and a checklist is formed with tabular interrogations corresponding to each uncertainty cause. The checklist enables decision makers to gain insight on the uncertainty level of the system at early steps as a convenient tool to review the adequacy of a TMDL program. Following the instruction of the checklist, an appropriate algorithm in a form of probability, possibility, or belief may then be assigned for the network. Consequently, the risk or evidence of the success of outcomes will be obtained. The incorporation of the systematic consideration of qualitative uncertainty into water quality management is expected to refine the decision-making process.
\end{abstract}

(C) 2006 Elsevier B.V. All rights reserved.

Keywords: Water quality management; Total maximum daily loads (TMDLs); Uncertainty analysis; Qualitative uncertainty; Checklist

* Corresponding author. No. 71, Chou-Shan Rd., Da-An District, Taipei, 106, Taiwan. Tel.: +886 23630406; fax: +886223928830.

E-mail address: hwma@ntu.edu.tw (H. Ma).

\section{Introduction}

Uncertainty is inevitable in any system and is likely to cause confusion in decision-making. It mainly stems from gaps in human knowledge due to the limited information available. To understand the unknown "real 
world," people seek reasonable explanations and develop rules according to their observations and experiences from the known world. However, even from observations, measurement uncertainties are associated with the precision of sampling and analysis methods (Lee and Ramsey, 2001).

Many documents have summarized the types of uncertainty. For example, the USEPA (1997) reported two kinds of uncertainty: variability and uncertainty. Variability refers to inherent difference, and uncertainty is normally derived from limited information and can be reduced if more information is given. In addition, Stewart (2000) illustrated aleatory uncertainty and epistemic uncertainty, and Morgan and Henrion (1990) proposed frequency uncertainty and subjective uncertainty. Young (2001) categorized uncertainty into hard uncertainty and soft uncertainty according to the quality of information. The definitions and causes of uncertainty summarized by Zimmermann (2000) are explicit. He defined uncertainty as one's inability to predict or prescribe a system, behaviors, or characteristics deterministically and numerically when the quantitative and qualitative information is not appropriate, and the existence of uncertainty is caused by lack of information, complexity, conflicting evidence, ambiguity, and belief. In the literature, qualitative uncertainty is acknowledged, but most research in water quality management has focused on quantitative uncertainty analysis, such as model parameter uncertainty (Scavia et al., 1981), model uncertainty (Reckhow, 1979), and natural randomness. Few studies have discussed qualitative uncertainty. One example is the fuzzy set theorem, which was used for linguistic vagueness (Mujumdar and Sasikumar, 2002). Among these studies, the discussions of qualitative uncertainty are limited. However, consideration of qualitative uncertainty is important to aid in estimation of the interior states of a system and to promote careful decision-making (Cerquides and de Mantaras, 1998; Doyle and Thomason, 1999). To foster complete understanding and to reduce uncertainty, both quantitative and qualitative uncertainties need to be estimated concurrently. Unfortunately, qualitative uncertainty has been neglected in most cases.

Unlike quantitative uncertainty, which is expressed conventionally as probability, qualitative uncertainty cannot be addressed as an estimated value and is always treated as "particular assumptions" without further analysis. For example, the choice of a feasible water quality model is important because the decision will be made according to the model predictions. However, the model selection might be determined without objective comparisons but rather be based simply on the modeler assumption that the behavior of hydrological and pollution transport is the same in different watersheds. This is a biased assumption. One point to be emphasized is that such subjective uncertainty can be found in any decision and has significant influences on subsequent decisions. In response to decisions being made based not on numerical probability but instead on subjective human preference, researchers began to address qualitative analysis and develop analysis methods, e.g., the qualitative relationship (Parsons, 1995), qualitative decision theory (Doyle and Thomason, 1999; Dubois et al., 2003), and the qualitative probability networks (Wellman, 1990). Qualitative uncertainty analysis aims to eliminate system vagueness and clarify the causality of factors in systems, facilitating more reliable decision-making.

Although the importance of qualitative uncertainty is recognized, it is hard to be verified by the current approaches due to the lack of explicit identification and clear analytic process for assessing qualitative uncertainty. Two purposes are addressed in this study. One is to clarify qualitative uncertainty by a comparison with quantitative one, and to develop a systematic analytic process as a tool for assisting more sound decisionmaking. The other is reviewing and identifying previously ignored qualitative factors in TMDL programs, which serves as a surrogate of water quality management. We here clarify the qualitative uncertain conditions in TMDL programs. A checklist with interrogations corresponding to each qualitative uncertainty replacing implicit and abstract concepts is generated. The checklist comprises possible uncertainty causes in TMDL programs and provides valuable information for building the qualitative network that depicts the relationship between uncertain factors.

Detailed explanations of qualitative uncertainty are addressed in Section 2, including an overview of the causes of uncertainty in water quality management and the TMDL. Section 3 illustrates the transformation of the conceptual understanding to a practical checklist. A TMDL program in Taiwan is used as a case study to illustrate the application of the qualitative uncertainty analysis collaborated with the checklist in Section 4. Finally, a discussion of the integration of qualitative uncertainty into water quality management is included in Section 5.

\section{Uncertainty}

\subsection{Qualitative uncertainty}

Qualitative uncertainty analyses (QUA) deal with various kind of knowledge-based issues. Since knowledge- 
based issues are complicated by subjective and abstract factors, QUA becomes an inexpressible art without explicit framework and analytic methodology. For example, in scenario analysis several situations or assumptions are made to evaluate concerned consequences. Due to human's inability to know exactly what will happen in the future, different scenarios are postulated to illuminate the potential outcomes. The setting of scenarios is obviously an uncertainty problem.

Qualitative uncertainty has been proposed systematically in the fields of decision analysis and artificial intelligence (Dubois and Prade, 1999; Dubois et al., 2003; Fargier and Sabbadin, 2005; Parsons and Saffiotti, 1996). There is no single definition of "qualitative," but it can be classified as "non-quantitative" according to a binary taxonomy. In contrast to the numerical results of quantitative uncertainty, qualitative uncertainty can be evaluated in the forms of qualitative probability, possibility, or belief (Parsons, 1995). Two main approaches discussed for dealing with qualitative uncertainty are the qualitative relationship and the qualitative decision theorem. Wellman (1990) and Parsons (1995, 2001) defined the qualitative algebra and computation for the qualitative relationship. When the issue of concern is the relationship between variables but not the quantity change of each variable, the qualitative relationship approach is a useful tool. The researchers are able to reduce the searchable range of potential factors by their qualitative relationship. Qualitative uncertainty includes biased/incorrect conceptual, methodological, epistemological, symbolic, and linguistic arguments. For example, the problem identification, model structure, specific assumptions, and system boundary setting are types of qualitative uncertainty issues (Sluijs et al., 2005). Qualitative analysis can manifest inherent information with narrative statements or logical language to complement the shortage of quantitative information. The action with the maximum expected utility is the best choice for a rational decision maker. However, the utility function is not always appropriate for all situations due to its quantitative characteristics. To respond to this situation, the qualitative decision theorem and hybrid qualitative-quantitative representation were generated.

The contribution of QUA, in its ability to elucidate qualitative relationships or to complement quantitative approaches in decision analysis, is to broaden the perspective from the restrained quantitative vision. Cerquides and de Mantaras (1998) indicated that the underlying meanings provoked by qualitative uncertainty can complete understanding of a target system and improve the Bayesian comprehensibility. Doyle and
Thomason (1999) concluded that the purpose of the qualitative decision theorem is refining the definition and explication of vague requirements and limitations. In other words, QUA helps unaware inner states to emerge and makes the target systems transparent with supplementary deliberations.

To clarify the difference of qualitative and quantitative uncertainty, we compare them in terms of their value, logic, language, function, management, analyzing objective, and use timing in Table 1. Among these characteristics, special discussions are placed on function, analyzing target, and use timing. QUA has the ability of examining uncertainty level over the whole system; therefore, it should be applied in the initial analysis phase as a screening mechanism. This is unlike quantitative uncertainty which is used for quantifying specific parameters. In addition, quantitative uncertainty analysis is limited to quantifiable element, such as numbers; qualitative uncertainty, however, is focused on not only the quality of numbers but also that of system states. Analyzing system states is a knowledge-based process with combination of expert judgment and available data. Because the QUA can provide an initial uncertainty level of system and reduce possible searching range, the time of use is prior to quantitative uncertainty analysis. Yet, while the quality of quantitative results is criticized, qualitative uncertainty analysis is a useful tool, such as NUSAP (Number Unit Spread Assessment Pedigree) system which results a diagnostic analysis to assess the quality of quantitative analysis (Funtowicz and Ravetz, 1990; Sluijs et al., 2005).

\subsection{A systematic procedure of qualitative uncertainty analysis}

Fig. 1 shows three types of relationship between uncertainty analysis and decision-making. In many situations, modeling is used to provide information and support decision-making. When the effects of uncertainty in modeling are ignored, such as Fig. 1(a), deterministic quantitative information will be employed

Table 1

The comparison of characteristics of qualitative and quantitative uncertainty

\begin{tabular}{lll}
\hline Characteristic & Qualitative uncertainty & Quantitative uncertainty \\
\hline Value & Non-numerical & Numerical \\
Logic & Subjective & Objective \\
Language & No specific language & Usually probability \\
Function & Screening & Quantifying \\
Analyzing target & States/numbers & Numbers \\
Use timing & Prior/post & Post \\
\hline
\end{tabular}


(a)

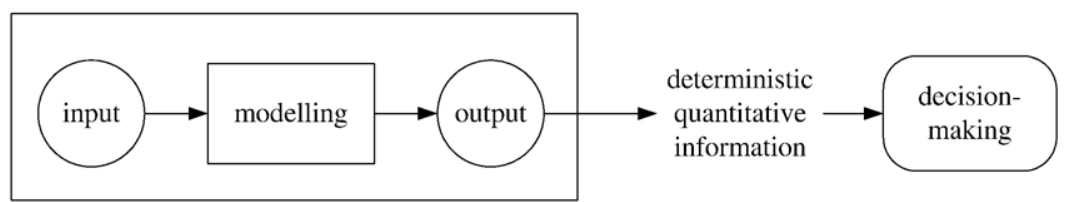

(b)

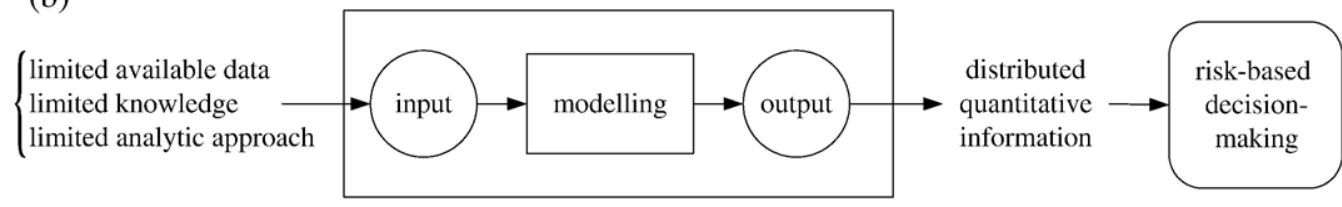

(c)

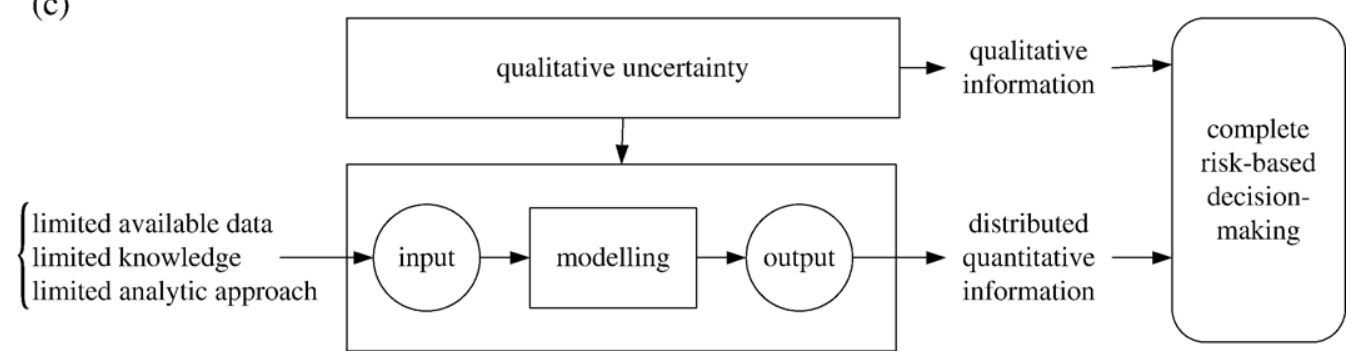

Fig. 1. Three types of relationship between uncertainty analysis and decision-making. (a) uncertainty is ignored and deterministic information from model prediction is used to support decision-making; (b) distributed information is generated by model parameter uncertainty and a risk-based decision-making is used; (c) qualitative uncertainty analysis is additionally included to serve as an overseer to make a more complete decisionmaking.

to support the decision. When the accuracy of model outputs receives increasing concerns because of the noise of uncertainty, the deterministic analysis is no longer satisfied. Many mathematical methods are then developed to deal with uncertainty from limited available data, knowledge, and analytic approach, such as Monte Carlo Method, First Order Sensitivity Analysis, Bayesian Inference, Fuzzy Set Theory, or combination of several algorithms. For example, McIntyre et al. (2003) and McIntyre and Wherter (2004) developed the WaterRAT tool with Regional Sensitivity Analysis (RSA), Generalized Likelihood Uncertainty Estimation (GLUE), Monte Carlo Markov Chain (MCMC), and Multi-objective Optimization for model identification. Massive researches are contributed to this stage and a risk-based decision-making is generated with distributed quantitative results, as illustrated in Fig. 1(b). The qualitative uncertainty discussed in this study goes beyond the framework of Fig. 1(b). The qualitative uncertainty explored in this study plays a role of overseer to supervise the system so as to facilitate a more complete decision-making. This QUA can be implemented by the following proposed procedure.
The systematic QUA is embodied in four steps. First, all potentially influential factors of the study system should be examined. An influence diagram is helpful to clarify the interactions of influential factors. The influence diagram is essential to illuminate the position of quantitative analysis for a complete uncertainty analysis and avoid the analysis being limited to quantifiable factors. Second, a checklist is formed with interrogations corresponding to each uncertain cause. Third, the expert judgment is inevitable to decide qualitative relationship between factors. An example of qualitative relationship is illustrated in Fig. 2. The qualitative relationship is built not only to delimit system boundary but also to define the causal inference between factors with qualitative algebra. Further discussions of qualitative algebra can be found in Wellman (1990) and Parsons (2001). Taking Fig. 2 as an example, the qualitative result of node 5 can be obtained from:

$\left(\delta_{1} \otimes \delta_{2}\right) \oplus \delta_{3} \oplus \delta_{4}$.

In Eq. (1), $\delta=\left[\frac{\partial \text { variable } x}{\partial \text { variable } y}\right]=[+-0$ ?], which refers to qualitative relationship. When the presence of variable 


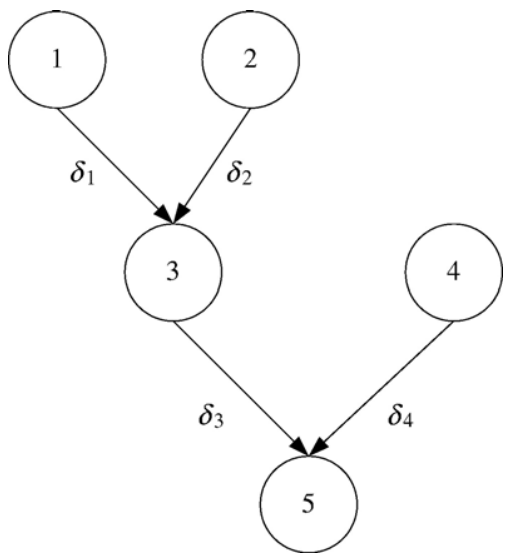

Fig. 2. A conceptual qualitative network that consists of factors' causality (represented by nodes and arrows) and their qualitative relationship $(\delta)$.

$x$ makes variable $y$ more likely than $x$ 's absence, the qualitative relationship is defined as $\delta=[+]$. In a probabilistic assertion, the positive influence is expressed as $\operatorname{Pr}(y \mid x) \geq \operatorname{Pr}(y \mid-x)$. Similarly, the negative influence is indicated as $[-]$; the circumstance of independence of variables is noted as [0], and [?] refers to the unknown influence.

Finally, the qualitative algorithm is formed. Unlike probability as the common language for quantitative uncertainty analysis, the algorithm used for qualitative analysis includes probability, possibility, and belief function. After deciding the function types of every factor (nodes), a qualitative probability network, a qualitative belief network, or a qualitative possibility network is established. The network providing a graphical description is useful for analyzing knowledge base issues. Finally, the information derived from the qualitative network is used to support decision-making.

In the subsequent sections, we will illustrate an application of this process on water quality management. The application is not intended to be complete because the assigned function and the uncertainty level of every influential factor needs rigorous evaluation by experts. The purpose is to demonstrate the analysis process. We will assess broadly the possible qualitative uncertainties in water quality management, which is frequently treated as premises (assumptions) and even without advanced considerations, and establish a checklist. The checklist that consists of qualitative uncertainty is helpful in constructing a qualitative network. The uncertainty level of a water quality management will be captured by examining the uncertainties in the checklist first. The interactions between factors are clarified as well. After deciding the network, one might go further to seek the function of every factor and build a network model for subsequent assessment. The type of the function is determined according to available information and knowledge base. For example, although probability function and belief function have some similarities, we have to assess which semantics are appropriate for the domain system (Cobb and Shenoy, 2003). Thus, instead of giving comments on the solutions for every uncertainty problems, this study demonstrates a QUA.

\subsection{The causes of uncertainty in water quality management and TMDL}

The study of uncertainty analysis in water quality management has been developed since the 1970s (Burges and Lettenmaier, 1975). The uncertainty at each decision-making step has been regarded as one of the main water quality management problems (Sasikumar and Mujumdar, 1998). The common causes of uncertainty in water quality management include the changing assimilative capacity of streams, unknown sources of nonpoint pollution, uncertainty associated with water quality simulation models and associated parameters, imperfect theoretical background, inaccurate and incomplete observed field data, and future disturbance. Many studies considered the quantitative effects, in particular model parameters and risk of predictions (Aalderink et al., 1996; Melching and Yoon, 1996; Melching and Bauwens, 2001; Suriyasilp et al., 2003). However, quantitative approaches do not solve all uncertainty problems. For example, because the quality and quantity of nonpoint sources of pollution are difficult to estimate, the control policies are not based on the precise pollution loadings but the estimated relationship between the land use and nonpoint pollution generation.

As an approach to water quality management, the TMDL faces the uncertainty problems addressed above. The TMDL is the total amount of waste loadings that a water body is able to receive without causing pollution. The traditional approach to dealing with uncertainty in TMDL is assigning a particular ratio for margin of safety (MOS), which is usually $10 \%$. However, a larger MOS restrains the allowable loadings of each pollution source, and a smaller MOS might result in an overoptimistic decision that fails to protect water quality. Therefore, Reckhow (2003) suggested that the MOS value should not be made arbitrarily without uncertainty analysis. A technological report of the USEPA (USEPA, 2002) also declared that one of the requirements for TMDL improvement is refining uncertainty analysis 
and statistical techniques. A number of researchers have noted some uncertainty problems in the TMDL procedure (Borsuk et al., 2002; Eheart and $\mathrm{Ng}, 2004$; Mujumdar and Vemula, 2004; Stow and Borsuk, 2003; Walker, 2003). These studies raised awareness of the urgency of uncertainty analysis in water quality management; nevertheless, discussions of qualitative analysis are still obscure and deficient.

To develop the QUA for TMDL programs, the system boundary, i.e. the influential factors, has to be identified. The following section systematically reviews uncertainty causes in TMDL with influence diagrams and eventually forms a concrete checklist to replace vague qualitative semantics.

\section{Qualitative uncertainty considerations of TMDL: review, identification, and transformation}

Significance of qualitative uncertainty effects on decision-making is acknowledged; however, little research on this subject has been done in the area of water quality management because of its subjective characteristics. Therefore, previous research rarely gave further consideration of qualitative uncertainty but rather made dogmatic assumptions about these uncertainty states. In this section, we establish a checklist to enable practical application of qualitative uncertainty through review, identification, and transformation.

The TMDL program was established by the United States in 1972 and became a dominant approach for water quality management in the early 1990s. According to Section 303(d) of the Clean Water Act, all states, territories, and authorized tribes are required to list impaired water bodies and develop a TMDL program to restore water quality. Once the water body is on the 303 (d) list, the following six-step TMDL process begins. First, the main water quality problem for the water body is identified, and one measurable criterion is identified according to the narrative water quality standard or desirable designated use of that water body. Next, all pollution sources within the watershed are assessed, including their quality, quantity, and distributions. Then, the assimilative capacity of the receiving water body is evaluated. In this step, the design flow is a key parameter to determine the capacity. The fourth step is the linkage of pollution sources and ambient water quality. A proper simulation model is needed in this step. The above four steps require considerable information. Unfortunately, uncertainty problems occur when information is lacking. After data collection, the waste load allocation, which consists of an optimization strategy, is applied to obtain the optimal allowable loadings for each source. Finally, a monitoring schedule consistent with the allocation scheme is planned, and the TMDL program is complete. In order to sketch the uncertainty involved in the TMDL procedure, rather than just focus on a particular type of uncertainty or a specific step, an influence diagram with systemic perspective is developed as in Fig. 3, and 15 primary causes are elicited from the six steps of the TMDL procedure. Reviewing uncertainty with an influence diagram has several advantages:

(1) Transparency. Clarifying the obscure portions of the system can reduce ambiguity and ignorance and strengthen TMDL effectiveness.

(2) Interaction. All elements in the influence diagram displayed graphically can eliminate duplicate examination and visualize the interaction among factors.

(3) Flexibility. New or additional uncertainty can be easily added to update the influence diagram.

After the uncertainty causes are reviewed, the definitions and qualitative implications are further described in Table 2. We transform the causes to corresponding interrogations to make the abstract concepts operational. All the questions on the checklist will be answered by modelers or decision makers with available information. The above questions are not easily responded by numerical methods; however, the confidence level of experts can be expressed by evidence mass function after assessing the target system with the checklist.

Several points are worth noting when applying the figure and table. First, a list like this is not intended to be exhaustive. Modification and expansion of the table may be needed in future work. Second, some of these listed uncertainty sources comprise both quantitative and qualitative aspects, such as the design flow. Although the qualitative uncertainty is particularly discussed in this study, the probable quantitative technology is encouraged to support further uncertainty analysis. Third, the factors in TMDL are interdependent because the program is a continuing, adaptive process. The uncertainties in previous steps may be inherited by subsequent steps. If the uncertainty at each step is not properly resolved, uncertainties will accumulate and intrude into decisions. For example, if pollution information in step 2 is not sufficient and complete, the predictions from water quality models in step 4 will not be reliable. Consequently, a big gap might be generated between the waste load allocation determined in step 5 and the actual condition. Due to the interactions, it is difficult to express explicitly the impact of each uncertainty on the whole system in quantitative approaches. 


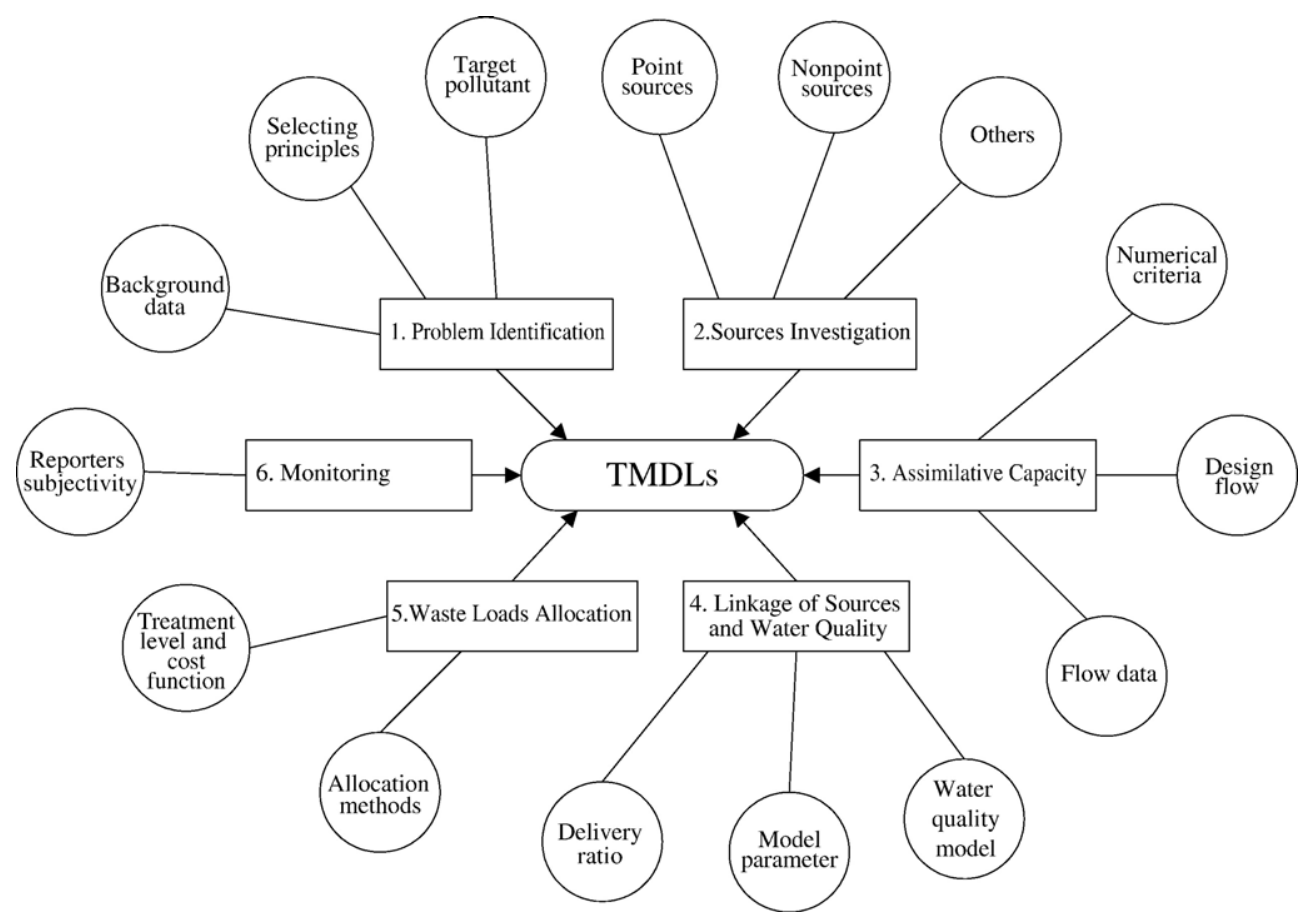

Fig. 3. The causes of uncertainty in the TMDL program.

3.1. Checklist: qualitative uncertainty analysis for TMDL programs

The checklist serves as a database of knowledge elicitation for the formation of qualitative network. Uncertainty level of each influential element is consequently determined by experts according to the results of the checklist investigation. The proposed checklist for TMDL programs consists of 15 uncertainty causes and is described in detail as follows.

\subsubsection{A. Problem identification}

A-1 What is the quality and quantity of the basic information of the target watershed (or river segments) concerning the spatial and temporal data?

A-2 What is the principle for listing and scaling a TMDL area?

A-3 How does a manager determine the measurable criteria?

The information required for water quality management comprises many aspects, especially data about pollution sources and the background environment, which are quality, quantity and distribution of point and nonpoint sources and the factors (or parameters, coefficients) associated with hydrology, geology, topog- raphy, climatology, and land use. A good management plan relies on complete and accurate databases. If the information is outdated, its use could negatively affect subsequent steps in the process. The given data must be consistent with requirements and must be elicited from valid sources. If there is a shortage of available data, a further inference with proper statistical technology is helpful. In order to strengthen the data quality, careful selection of the sampling scheme and measurement tools will enhance the accuracy of the data collected.

The identification of an impaired water body is a crucial judgment to determine the list of TMDLs, which are on the 303(d) list in the Clean Water Act in the United States. The listing of a water body on the 303(d) list is based on the violation of the water quality criterion selected for a particular designated use. The numerical water quality criterion representing the designated use requirements should be specific and adequate. A desirable criterion consists of magnitude, duration and frequency (NRC, 2001). In the U.S., a frequency of $10 \%$ exceeding the concentration standard is commonly used to determine whether the water quality standard is met. However, even integrating the probability into the criterion, statistical error problems may occur as well (Smith et al., 2001; Shabman and Smith, 2003). In spite of the quantitative uncertainty of the criterion, determination of numerical criteria and a particular violation percentage is a 
Table 2

The checklist for assessing water quality management, consisting of elicited uncertainty causes, associated descriptions and interrogations

\begin{tabular}{|c|c|c|c|}
\hline Steps & $\begin{array}{l}\text { Uncertainty } \\
\text { causes }\end{array}$ & Description & Interrogation \\
\hline \multirow[t]{3}{*}{$\begin{array}{l}\text { Problem } \\
\text { identification }\end{array}$} & Background data & $\begin{array}{l}\text { Inaccuracy, imprecision, or incompleteness of watershed background } \\
\text { and baseline data, including geological, geographical, and climate } \\
\text { data as well as distributions of pollution sources, would lead to } \\
\text { incorrect identification of the problem. }\end{array}$ & $\begin{array}{l}\text { A- } 1 \text { What is the quality and quantity of the basic information of the } \\
\text { target watershed (or river segments) concerning the spatial and } \\
\text { temporal data? }\end{array}$ \\
\hline & Selecting principles & $\begin{array}{l}\text { The uncertainties in the selection of TMDL candidate areas as } \\
\text { well as in watershed boundary delineation produce obscure principles. }\end{array}$ & A-2 What is the principle for listing and scaling a TMDL area? \\
\hline & Target pollutant & The choice of target pollutant influences the allocation schemes. & A-3 How does a manager determine the measurable criteria? \\
\hline \multirow[t]{3}{*}{$\begin{array}{l}\text { Sources } \\
\text { investigation }\end{array}$} & $\begin{array}{l}\text { Point sources } \\
\text { (PS) information }\end{array}$ & $\begin{array}{l}\text { The observations involve measurement uncertainty and cause } \\
\text { inaccurate information. }\end{array}$ & $\begin{array}{l}\text { B-1 For point sources (PS), does the sampling or monitoring data reflect } \\
\text { the actual pollution generation in consideration of the sampling location, } \\
\text { frequency and measurement methods? }\end{array}$ \\
\hline & $\begin{array}{l}\text { Nonpoint sources } \\
\text { (NPS) information }\end{array}$ & $\begin{array}{l}\text { Nonpoint sources are always with uncertain quantity, quality and } \\
\text { distributions. }\end{array}$ & $\begin{array}{l}\text { B-2 For nonpoint sources (NPS), due to the difficulty of measuring NPS, } \\
\text { how reliable are the results from simulation models or empirical } \\
\text { equations? }\end{array}$ \\
\hline & Others & $\begin{array}{l}\text { The relationships between PS and NPS, upstream and downstream, } \\
\text { are uncertain. }\end{array}$ & $\begin{array}{l}\text { B-3 Is there any connection/relationship between PS and NPS and the } \\
\text { impact from upstream to downstream? }\end{array}$ \\
\hline \multirow[t]{3}{*}{$\begin{array}{l}\text { Assimilative capacity } \\
\text { of water body }\end{array}$} & Numerical criteria & $\begin{array}{l}\text { The validness of water body categorization and associated numerical } \\
\text { criteria influence the recognition of water quality. }\end{array}$ & $\begin{array}{l}\text { C-1 Does the water quality standard (numerical criteria) accurately } \\
\text { represent the water quality? }\end{array}$ \\
\hline & Design flow & $\begin{array}{l}\text { The choice and definition of design flow affects the determination of } \\
\text { assimilative capacity of water body and thus the waste allocation and } \\
\text { protection of water quality. }\end{array}$ & C-2 What design flow is used for capacity loading of the water body? \\
\hline & Flow data & $\begin{array}{l}\text { The accuracy and proper usage of flow records affects the } \\
\text { determination of the assimilative capacity. }\end{array}$ & $\begin{array}{l}\text { C-3 How accurate are the stream flow records, i.e. the locations of flow } \\
\text { gages, recording length, and natural variability? }\end{array}$ \\
\hline \multirow[t]{3}{*}{$\begin{array}{l}\text { Linkage of sources } \\
\text { and water quality }\end{array}$} & Water quality model & $\begin{array}{l}\text { The use of different water quality simulation models produces } \\
\text { uncertain prediction of impact. }\end{array}$ & D-1 Is the chosen water quality model appropriate? \\
\hline & Model parameters & Model parameters require calibration and verification. & D-2 Are the model parameters calibrated and verified? \\
\hline & Delivery rate & $\begin{array}{l}\text { The delivery rate, which represents the difference between a pollution } \\
\text { generation source and a receiving water body, influences waste } \\
\text { allocation scheme. }\end{array}$ & $\begin{array}{l}\text { D-3 Is the uncertainty in the delivery/transport process between pollution } \\
\text { source generation and the receiving water body taken into account? }\end{array}$ \\
\hline \multirow[t]{2}{*}{$\begin{array}{l}\text { Waste loads } \\
\text { allocation }\end{array}$} & Allocation method & $\begin{array}{l}\text { Different allocation methods induce different pollution elimination } \\
\text { rates for individual pollution source. }\end{array}$ & $\begin{array}{l}\text { E-1 How does the decision maker determine the most appropriate } \\
\text { allocation methods from several candidate approaches? }\end{array}$ \\
\hline & $\begin{array}{l}\text { Waste treatment level } \\
\text { and cost function }\end{array}$ & $\begin{array}{l}\text { Both waste treatment technology and cost are the basic information } \\
\text { in allocation optimization programming. }\end{array}$ & $\begin{array}{l}\text { E-2 How reasonable are the associated assumptions in the optimization } \\
\text { programming, e.g., cost function and feasible treatment level? }\end{array}$ \\
\hline Monitoring & $\begin{array}{l}\text { Reporters } \\
\text { subjectivity }\end{array}$ & $\begin{array}{l}\text { The subjectivity and belief of monitoring reporters might cause a } \\
\text { bias in assessing performance of water quality policy. }\end{array}$ & $\begin{array}{l}\text { F-1 Does the monitoring report reflect the true water quality without } \\
\text { biased and subjective manipulation? }\end{array}$ \\
\hline
\end{tabular}


qualitative uncertainty problem and cannot be decided arbitrarily. Additionally, the definition of TMDL regions is a critical issue as well. The designation of the listing principle is usually based on the results of water quality monitoring. Therefore, to decide the boundary of a TMDL program usually has to accommodate sampling locations. The scale of sampling locations might not clearly segment the distribution of pollution sources, and pollution control actions might be made inappropriately due to the up- or down-stream influence or the indefinite contribution from nonpoint sources. Therefore, the confidence of the recognition of the impairment of water quality and the delineation of control regions (or subdivisions) is very important in a TMDL program.

\subsubsection{B. Pollution sources investigation}

B-1 For point sources (PS), does the sampling or monitoring data reflect the actual pollution generation in consideration of the sampling location, frequency and measurement methods?

B-2 For nonpoint sources (NPS), due to difficulty of measuring NPS, how reliable are the results from simulation models or empirical equations?

B-3 Is there any connection/relationship between PS and NPS and the impact from upstream to downstream?

Ideally, pollution information is obtained from on-site sampling, and these observations are then used as certain data. Unfortunately, due to limited resources, sampling is seldom complete and continuous, so the collected data may be distorted because of qualitative uncertainty. For example, factors such as whether the data are sampled upstream or downstream, in the morning, at night, or in winter or summer may affect the authenticity of the data. In addition, the measurement methods need to be accurate and bad manipulation avoided. While modeling is employed to evaluate pollution distribution and quantities, uncertainty is a significant nuisance in modeling. For example, different models might lead to different conclusions, and the uncertainty of associated parameters renders the results non-convincing. While empirical formulas are used as evaluation tools, it is important to notice the specific assumptions and constraints in previous experiences and to check the model adequacy when applying the formulas. Pollution investigations, either from observed data or simulation models, are usually regarded as certain data in TMDL programs; therefore, every effort should be made to ensure their quality. The reliability of the pollution source information is the foundation of water quality management. It is not proper to manage water quality by depending on assumptions without calibration and verification.
Additional uncertainty questions regarding the connection (tradeoff) between PS and NPS may be encountered in this step. In a TMDL program, the allowable loadings for PS and NPS are included. However, an appropriate approach to incorporate NPS into the waste load allocation (WLA) of PS has not yet been developed. For example, a case study of Chatfield Basin in Colorado proposed cost functions of both PS and NPS and suggested that the PS must be reduced completely prior to any NPS reduction because the treatment cost of NPS reductions is much higher than that of PS (USEPA, 1999).

\subsubsection{Assimilative capacity of a waterbody}

C-1 Does the water quality standard (numerical criteria) accurately represent the water quality?

C-2 What design flow is used for capacity loading of the water body?

C-3 How accurate are the stream flow records, i.e. the locations of flow gages, recording length, and natural variability?

The assimilative capacity of the receiving water body is the base on which a TMDL program is carried out. The capacity is simply obtained from the flow discharge multiplying by water quality standard (i.e., numerical concentration criteria); therefore, the uncertainty problems in the step can be discussed in terms of the water quality criteria and the river flow. The characteristic of the numerical criteria is discussed in the previous step, and its implication in qualitative uncertainty is illustrated in this step.

Water bodies are classified according to their desirable usage, and the numerical criteria are designed to be a measurable standard to assess water quality. Reckhow et al. (2005) indicated that the numerical criterion must be a proper predictor and compatible with a narrative designated-use statement. NRC (2001) suggested that a prelist for reviewing the adequacy of concentration criteria and the designated use of a water body before a formal TMDL list helps to avoid wasting resources on unimpaired water bodies. Use Attainability Analysis (UAA) is a proposed approach for assessing the designated use of a water body (Novotny, 1996; NRC, 2001).

The randomness of stream flow influences the evaluation of water quality as well. Allocating total waste loadings requires determination of not only pollution concentration criteria but also a particular water condition. The low flow is usually used to evaluate the assimilative capacity, such as $\mathrm{Q}_{90}, \mathrm{Q}_{75}$, or $\mathrm{Q}_{7,10}$ (the seven-day, ten-year low flow used mostly in the U.S.), significantly affects the waste allocation. For example, 
using $\mathrm{Q}_{90}$ as the design flow allows less pollution discharge of sources than using $\mathrm{Q}_{75}$. The determination and calculation of the design flow for the WLA should be based on considerable investigations. Because the low flow is usually assigned for water quality control and is influenced significantly by the particular record length (Vogel and Fennessey, 1994), the uncertainty of the analysis methods and of the given data should be assessed. In addition, the assimilative capacity of a waterbody will vary seasonally. The seasonal variability of stream flow is believed to impinge on water quality management, especially in areas where the flow varies dramatically from one season to another.

\subsubsection{Linkage of pollution sources and water quality}

D-1 Is the chosen water quality model appropriate?

D-2 Are the model parameters calibrated and validated?

D-3 Is the uncertainty in the delivery/ transport process between pollution source generation and the receiving water body accounted for?

Water quality models are used to link pollution sources and water quality, and the uncertainty related to models is discussed widely and well documented (Beck and van Straten, 1983). Instead of discussing the quantification of uncertainty, we suggest three interrogations to improve the robustness of model implementation in the use of water quality models. First, a model, either a packaged model or an empirical model, has to be chosen thoughtfully and prudently. Chapra (2003) claimed that water quality modeling is not a "commodity industry" but rather an "academics-based discipline." He also suggested that modelers must take note of the inconsistencies between sampling and the underlying assumptions in the models. This is concordant with qualitative uncertainty considerations. The use of different models probably leads to different decisions. NRC (2001) reported model selection criteria, including adequate endpoint definition, practical complexity, data availability, budget, and flexibility.

After a model is selected, the next task is calibration and verification of the model. Model parameters are plausible values rather than actual values reflecting natural phenomena. Therefore, confirmation of model fitness is required. The observed events used as calibration imply the validity of parameters at that particular period or in that particular situation, and the various observations are required as verification events. However, limited by available resources, the sampling observations are probably not sufficient for both calibration and verification. Too few observations are hard to support the solid verification of models. The third question indicates the difference in pollution amount between the source generation and the transport process, which will cause different water quality predictions in the receiving water body. A simple expression of this situation is the use of a delivery ratio. If the pollution source is not near the receiving water body, the moderation of pollution delivery must be estimated.

\subsubsection{E. Waste loads allocation}

E-1 How does the decision maker determine the most appropriate allocation from several approaches?

E-2 How rational are the associated assumptions in optimization programming, e.g., cost function and feasible treatment level?

The qualitative uncertainty in this step stems primarily from the subjective choice of the allocation method and the assumptions of associated parameters. The query of choosing a waste load allocation (WLA) is similar to that of choosing an adequate water quality model. The WLA is conducted by a water quality simulation model and allocation optimization programming. The qualitative uncertainty of the model was discussed in the previous section; this section focuses on the uncertainty attached to the optimization strategy. The various allocation methods are based on special concerns; for example, the objective of equal treatment removal rate (ETR) emphasizes equality, and the minimum cost method (MCM) pursues economic efficiency. In addition to the 19 approaches reported by the USEPA (1991), minimum water quality violation (Burn and Lence, 1992) and extending designs like ETR for sub-region or industrial types (EPA of Republic of China, 1996) have also been proposed. Among these allocation approaches, MCM is frequently used ( $\mathrm{Li}$ and Morioka, 1999; Rossman, 1989; Somlyódy et al., 1994), especially in cases where budgets are limited. However, the cost consideration is not always the best allocation, and the optimal treatment cost might not be consistent with the optimal social cost. Different allocation approaches result in different waste allocations. To address this uncertainty, different allocation principles may be combined, thereby forming a multi-objective program, in which a Pareto optimal solution will be sought for.

After selecting the allocation method, i.e., the objective function, the proper assignment of factors in constraints is needed. For example, the assumption of the boundary of removal rate has to be compatible with a feasible treatment technology and not to be selected prematurely. Similarly, the cost function has to be justified. Because the MCM is used frequently, its precision is particularly important. However, the individual 
cost function for each source is difficult to estimate. Despite the variance among pollution sources, modelers usually apply a single cost empirical function to all sources, which might produce controversy concerning the optimal removal rate.

\subsubsection{F. Monitoring}

F-1 Does the monitoring report reflect the true water quality without biased and subjective manipulation?

The monitoring plan refers to the sampling plan, by which researchers diagnose the performance of the TMDL program through water quality observation, like a post audit. Assessment of whether or not water quality has improved is based on researcher judgment according to extensive observations. The reporter's personal opinions as well as his or her knowledge are imposed on the explanation and evaluation of sampling data. Although sampling is an objective event, the subjective explanation may cloud accurate evaluation of the success or failure of the TMDL.

In the U.S., monitoring plans are estimated biennially. This routine task benefits understanding of the performance of a water policy (if the personal belief of reporters is eliminated). In addition, the design of monitoring plans could induce inconsistencies between predicted and actual values. For example, the design of a sampling strategy includes the types of pollutants, and the sampling time schedule must be compatible with model simulation because some pollution concentrations fluctuate depending on the time of day (Chapra,
2003). The location of water quality monitoring gages influences results as well; an entire water body may be judged based on measurements taken in special stream segments (Smith et al., 2001). The question proposed in this step is aimed at avoiding an incorrect judgment about the performance of a TMDL program and promoting better sampling design.

\section{Example: assessing water quality management in Taiwan with qualitative uncertainty analysis}

The study of TMDLs in Taiwan began in 1988, and the TMDL regulation was legislated in the amended Water Pollution Control Act in 1992. According to reports from the Environmental Protection Administration in Taiwan in 2003, 40.5\% of natural rivers are polluted, and over $50 \%$ of reservoirs suffer from eutrophication. The reports reveal that an adequate and efficient water quality management is urgently required. Several research projects have studied the application of TMDLs in Taiwan; however, there has been no practical case implemented to date. A project about pollution control planning in Kau-Ping River basin was the most complete TMDL program studied in Taiwan (EPA of Republic of China, 2000). This report is a three-year project comprising most of the steps of a TMDL program and thus used as a case study to demonstrate the application of the checklist in Table 2 and the qualitative network.

The assessment of the case project with the checklist is an expert appraisal process. Obtained from the evaluation

Table 3

A hypothetical result of qualitative uncertainty analysis for case study

\begin{tabular}{|c|c|c|c|}
\hline $\begin{array}{l}\text { Influential } \\
\text { factor }\end{array}$ & Results from the review of the checklist & $\begin{array}{l}\text { Evidence mass } \\
\text { function }\end{array}$ & Value \\
\hline A1 & Data was collected from valid database and 3's (GIS/GPS/RS) was used. & $m(\mathrm{~A} 1)$ & 0.8 \\
\hline A2 & No principle was applied for scaling the TMDL area. The entire Kao-Ping River basin was employed. & $m(\mathrm{~A} 2)$ & 0.5 \\
\hline A3 & $\begin{array}{l}\text { BOD and } \mathrm{NH}_{3}-\mathrm{N} \text { were the target pollutants for PS pollution control, and TN and TP were identified } \\
\text { for NPS control. }\end{array}$ & $m(\mathrm{~A} 3)$ & 0.9 \\
\hline B1 & Sound analysis with the updated available information was used. & $m(\mathrm{~B} 1)$ & 0.7 \\
\hline B2 & Data was collected from valid and updated database but not complete. & $m(\mathrm{~B} 2)$ & 0.6 \\
\hline B3 & The trade-off of PS and NPS was considered in this project. & $m(\mathrm{~B} 3)$ & 0.5 \\
\hline $\mathrm{C} 1$ & The water quality standard has not been adjusted and might be not proper. & $m(\mathrm{C} 1)$ & 0.3 \\
\hline $\mathrm{C} 2$ & Low flow as $\mathrm{Q}_{75}$ and $\mathrm{Q}_{90}$ was discussed and $\mathrm{Q}_{90}$ was finally decided as the design flow. & $m(\mathrm{C} 2)$ & 0.6 \\
\hline $\mathrm{C} 3$ & No detailed analysis was made for the stream flow record, but seasonal variability was discussed. & $m(\mathrm{C} 3)$ & 0.5 \\
\hline D1 & QUAL2E and GWLF were chosen for water quality and NPS pollution, respectively. & $m(\mathrm{D} 1)$ & 0.8 \\
\hline $\mathrm{D} 2$ & $\begin{array}{l}\text { The two models were calibrated with limited data. One measurement was carried out at } 46 \text { sampling } \\
\text { sites along the river for the evaluation of PS pollution. Three stormwater events were sampled at } \\
\text { four different land-use sites. }\end{array}$ & $m(\mathrm{D} 2)$ & 0.5 \\
\hline D3 & No spatial variability (effects of delivery/transport) was considered. & $m(\mathrm{D} 3)$ & 0.4 \\
\hline E1 & Minimum cost was intuitively chosen as the objective function. & $m(\mathrm{E} 1)$ & 0.2 \\
\hline E2 & The associated parameters were given appropriate assignment. & $m(\mathrm{E} 2)$ & 0.8 \\
\hline F1 & No suggestion was made for further morning reports. & $m(\mathrm{E} 3)$ & 0.1 \\
\hline
\end{tabular}


process, the uncertainty level of each component in the qualitative network will be measured and the confidence of an appropriate decision will be revealed. The results in Table 3 were not generated through a detailed expert diagnosis. They are used in this article for the purpose of demonstrating the process, employing the belief function as applied algorithm. If the appropriate calculation method is decided, the uncertainty level of overall system will be identified. To simplify the calculation, independence is assumed between factors. The total evidence mass function of each factor is one, i.e. $\sum m(i)=1$. The mass function of factor $i$ derived from expert elicitation is then a value between zero and one. Therefore, a perfect decision with definite certainty in the case project will get point 15 from Eq. (2). According to Table 3, the evidence of the certainty of the TMDL program is 8.2 obtained from Eq. (3).

$$
\begin{aligned}
m= & m(A 1) \oplus m(A 2) \oplus m(A 3) \oplus m(B 1) \oplus m(B 2) \oplus m(B 3) \\
& \oplus m(C 1) \oplus m(C 2) \oplus m(C 3) \oplus m(D 1) \oplus m(D 2) \\
& \oplus m(D 3) \oplus m(E 1) \oplus m(E 2) \oplus m(F 1)
\end{aligned}
$$

$$
\begin{aligned}
m= & 0.8+0.5+0.9+0.7+0.6+0.5+0.3+0.6 \\
& +0.5+0.8+0.5+0.4+0.2+0.8+0.1=8.2 .
\end{aligned}
$$

Since point 15 represents a decision without any uncertainty, the point 8.2 gives an insight about the uncertainty level of the case project. Such information is valuable for decision makers to have an understanding about the confidence of the outcome from their system. The size and complexity of the qualitative network can be modified according to decision makers' requirement. Furthermore, if correlation between factors is concerned, the joint probability and conditional probability with the belief function could be used.

\section{Conclusion}

In decision-making, some uncertainty can be quantified explicitly; however, qualitative uncertainty may affect the accuracy of quantitative results and even mislead decisions. Qualitative uncertainty is nonquantitative and plays a significant role in decision analysis in subjective, preference, symbolic, or linguistic problems. Qualitative uncertainty represents an agent's local states, the set of internal states under its current knowledge (Brafman and Tennenholtz, 1996). The state of the world is outward and objective, while the local state of agency is inward and subjective.
Qualitative uncertainty in water quality management, like the various internal states of each step, has been given little attention. This study has tried to clarify the characteristics of qualitative uncertainty and built a systematic analysis process to refine decision-making. Through review of the TMDL procedure with influence diagrams and identification of potential factors, a checklist was formed with 15 interrogations as a concrete estimation instead of abstract notions.

The checklist is not intended to solve water quality problems immediately; rather, it provides a comprehensive inspection approach to follow and seeks improvement for the future design of TMDL programs. It is an informative tool to reduce unnecessary trials. A water quality management plan is constructed by a series of decisions, each of which is discrete but also dependent on the others. That means that uncertainty associated with any step beginning with the first may influence subsequent steps. Parts of the impact can be described by a quantitative algorithm, such as the analysis of uncertainty of model parameters, but some impacts in non-quantitative states are difficult to evaluate physically. The impact on the overall system of either quantitative or qualitative uncertainty cannot be discerned clearly with current knowledge; however, the disturbances of qualitative uncertainty can be moderated by a deliberative checklist, which can facilitate the formulation of more detailed qualitative analysis to reveal the uncertainty level of the whole system. The result of the systematic analysis, and more importantly, the deliberation process itself, are expected to improve the efficiency of water quality management.

\section{References}

Aalderink R, Zoeteman A, Jovin R. Effect of input uncertainties upon scenario predictions for the River Vecht. Water Sci Technol 1996;33(2):107-18.

Beck M, van Straten G. Uncertainty and forecasting of water quality. Berlin: Springer-Verlag; 1983. 386 pp.

Borsuk M, Stow C, Reckhow K. Predicting the frequency of water quality standard violations: a probabilistic approach for TMDL development. Environ Sci Technol 2002;36(10):2109-15.

Brafman R, Tennenholtz M. On the foundations of qualitative decision theory. AAAI 1996:1291-6.

Burges S, Lettenmaier D. Probabilistic methods in stream quality management. Water Resour Bull 1975;11(1):115-30.

Burn D, Lence B. Comparison of optimization formulations for wasteload allocations. J Environ Eng ASCE 1992;118(4):597-612.

Cerquides J, de Mantaras R. Knowledge discovery with qualitative influences and synergies. Lect Notes Artif Int 1998;1510:273-81.

Chapra S. Engineering water quality models and TMDLs. J Water Resour Plan Manage ASCE 2003;129(4):247-56.

Cobb B, Shenoy P. A comparison of Bayesian and belief function reasoning. Inf Syst Front 2003;5(4):345-58. 
Doyle J, Thomason R. Background to qualitative decision theory. AI Mag 1999;20(2):55-68.

Dubois D, Prade H. Qualitative possibility theory and its applications to constraint satisfaction and decision under uncertainty. Int J Intell Syst 1999;14:45-61.

Dubois D, Fargier H, Sabbadin R. Qualitative decision rules under uncertainty. Lect notes artif int, symbolic and quantitative approaches to reasoning with uncertainty, 7th European Conference ECSQARU; 2003. p. 1-21.

Eheart $\mathrm{J}, \mathrm{Ng}$ T. Role of effluent permit trading in Total Maximum Daily Load Programs: overview and uncertainty and reliability implications. J Environ Eng ASCE 2004;130(6):615-21.

EPA of Republic of China. The development of water quality and study of TMDL Program II: the study of water quality management in river basin and the development of TMDL assessment model. EPA-85-E3G1-09-05; 1996. [in Chinese].

EPA of Republic of China. The study of enterprise wastewater management - the optimal strategy of pollution reduction and management system, EPA-89-U1G1-03-117; 2000. [in Chinese].

Fargier H, Sabbadin R. Qualitative decision rules under uncertainty: back to expected utility. Artif Intell 2005;164:245-80.

Funtowicz S, Ravetz J. Uncertainty and quality in science for policy. Dordrecht: Kluwer; 1990. 244 pp.

Lee J, Ramsey M. Modelling measurement uncertainty as a function of concentration: an example from a contaminated land investigation. Analyst 2001;126:1784-91.

Li S, Morioka T. Optimal allocation of waste loads in a river with probabilistic tributary flow under transverse mixing. Water Environ Res 1999;71(2):156-62.

McIntyre N, Wherter H. A tool for risk-based management of surface water quality. Environ Model Softw 2004;19:1131-40.

McIntyre N, Wagener T, Wherter $\mathrm{H}$, Yu Z. Uncertainty and risk in water quality modeling and management. J Hydroinform 2003;4: 259-74.

Melching C, Bauwens W. Uncertainty in coupled nonpoint source and stream water-quality models. J Water Resour Plan Manage ASCE 2001;127(6):403-13.

Melching C, Yoon C. Key sources of uncertainty in QUAL2E model of Passaic River. J Water Resour Plan Manage ASCE 1996;122(2): 105-13.

Morgan M, Henrion M. Uncertainty: a guide to dealing with uncertainty in quantitative risk and policy analysis. Cambridge University Press; 1990. 344 pp.

Mujumdar P, Sasikumar K. A fuzzy risk approach for seasonal water quality management of a river system. Water Resour Res 2002;38(1): 5-1-9.

Mujumdar P, Vemula V. Fuzzy waste load allocation model: simulationoptimization approach. J Comput Civ Eng 2004;18(2):120-31.

National Research Council (NRC). Assessing the TMDL approach to water quality management. Washington DC: National Academy Press; 2001. 122 pp.

Novotny V. Integrated water quality management. Water Sci Technol 1996;33(4-5):1-7.

Parsons S. Further results in qualitative uncertainty. Int J Uncertain Fuzziness Knowl Based Syst 1995;3(1):187-210.

Parsons S. Qualitative methods for reasoning under uncertainty. Cambridge: The MIT Press; 2001. 400 pp.

Parsons S, Saffiotti A. A case study in the qualitative verification and debugging of numerical uncertainty. Int J Approx Reason 1996;14: 187-216.

Reckhow K. The use of a simple model and uncertainty analysis in lake management. Water Resour Bull 1979;15(3):601-11.
Reckhow K. On the need for uncertainty assessment in TMDL modeling and implementation. J Water Resour Plan Manage ASCE 2003;129(4):245-6.

Reckhow K, Arhonditsis G, Kenney M, Hauser L, Tribo J, Wu C, et al. A predictive approach to nutrient criteria. Environ Sci Technol 2005;39(9):2913-9.

Rossman L. Risk equivalent seasonal waste load allocation. Water Resour Res 1989;25(10):2083-90.

Sasikumar K, Mujumdar P. Fuzzy optimization model for water quality management of a river system. J Water Resour Plan Manage ASCE 1998;124(2):79-88.

Scavia D, Canale R, Powers W, Moody J. Variance estimates for a dynamic eutrophication model of Saginaw Bay Lake Huron. Water Resour Res 1981;17:1115-24.

Shabman L, Smith E. Implications of applying statistically based procedures for water quality assessment. J Water Resour Plan Manage ASCE 2003;129(4):330-6.

Sluijs J, Craye M, Funtowicz S, Kloprogge P, Ravetz J, Risbey J. Combining quantitative and qualitative measures of uncertainty in model-based environmental assessment: the NUSPA system. Risk Anal 2005;25(2):481-92.

Smith E, Ye K, Hughes C, Shabman L. Statistical assessment of violations of water quality standards under Section 303(d) of the Clean Water Act. Environ Sci Technol 2001;35(3):606-12.

Somlyódy L, Kularathna M, Masliev I. Development of least-cost water quality control policies for the Nitra River Basin in Slovakia. Water Sci Technol 1994;30(5):69-78.

Stewart T. Uncertainty, judgment, and error in prediction. In: Sarewitz D, Pielke R, Byerly R, editors. Prediction: science, decision making, and the future of nature. Washington DC: Island Press; 2000. p. 41-57.

Stow C, Borsuk M. Assessing TMDL effectiveness using flowadjusted concentrations: a case study of the Neuse River, North Carolina. Environ Sci Technol 2003;37(10):2043-50.

Suriyasilp T, Graettinger A, Durrans S. Quantitatively directed sampling for main channel and hyporheic zone water-quality modeling. Adv Water Resour 2003;26:1029-37.

USEPA. Technical support document for water quality-based toxics control. http://yosemite.epa.gov/water/owrccatalog.nsf/0/ 025cb4267d4d9fd585256b060072539a\%3FOpenDocument. 1991.

USEPA. Exposure factors handbook. Washington, DC: National Center for Environment Assessment, Office of Research and Development National Center for Environmental Assessment; 1997.

USEPA. Protocol for developing nutrient TMDLs. EPA841-B-99-007; 1999.

USEPA. The twenty needs report: how research can improve the TMDL program. EPA 841-B-02-002. Washington, DC: Assessment and Watershed Protection Division; 2002.

Vogel R, Fennessey N. Flow-duration curves I: new interpretation and confidence intervals. J Water Resour Plan Manage ASCE 1994;120(4):485-504.

Walker Jr W. Consideration of variability and uncertainty in phosphorus total maximum daily loads for lakes. J Water Resour Plan Manage ASCE 2003;129(4):337-44.

Wellman M. Fundamental concepts of qualitative probabilistic networks. Artif Intell 1990;44:257-303.

Young R. Uncertainty and the environment. Cheltenham, UK: Edward Elgar; 2001. 249 pp.

Zimmermann H. An application-oriented view of modeling uncertainty. Eur J Oper Res 2000;122:190-8. 